\title{
Endoscopic treatment of a symptomatic duodenal duplication cyst
}

We present the case of a 36-year-old man without previous medical history who was admitted because of protracted colic-like abdominal pain in the right upper quadrant. His symptoms had started a few days previously, but had persisted and were accompanied by vomiting. In his history, the patient mentioned having experienced several previous attacks of similar pain over a period of several years. Clinical examination was unremarkable. A work-up, first by means of computed tomography ( $\triangleright$ Fig. 1 ) and later by magnetic resonance imaging ( $\mathbf{F i g . 2}$ ), showed a bulging mass-like cystic lesion at the level of the papilla with retention of what appeared to be an intralesional stone. The biliopancreatic duct system seemed intact.

To further differentiate between congenital (choledochocele type III or duodenal duplication cyst), neoplastic, or other etiology, we performed a duodenoscopy in conjunction with an endoscopic ultrasound (EUS). Conventional endoscopic examination showed a soft, large, and smooth bulging mass ( $>$ Video 1 ) overlying the expected papillary region. On EUS, this was compatible with a spherical, elongated hollow structure that showed the typical gastrointestinal layered architecture and contained echogenic material with acoustic shadowing in the region of the major papilla. The diagnosis of a duodenal duplication cyst with an enterolith was therefore upheld.

Endoscopic resection of the duplication cyst was performed with a standard polypectomy snare ( $\downarrow$ Video 1$)$. The fragments, including the retained stone in a mucosal pocket ( $\mathbf{F i g . 3}$ ), were captured by means of a Roth net. After resection, cannulation of the pancreatic and biliary tract showed structural integrity and excluded a biliopancreatic junction anomaly. The procedure was uneventful. Pathologic examination of the resected specimen showed duodenal mucosa without evidence of dysplasia.

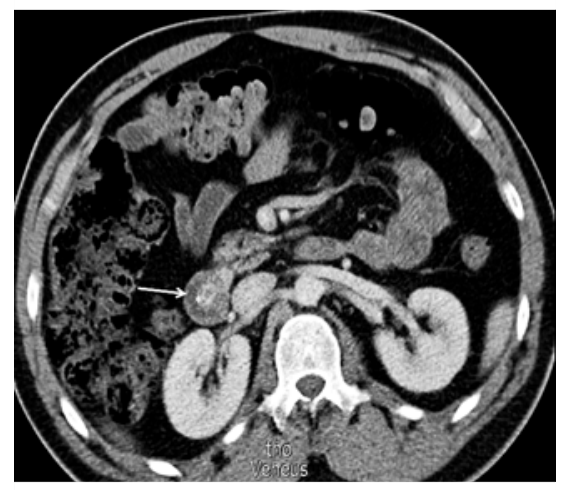

- Fig. 1 Computed tomography axial image showing a bulging mass-like cystic lesion at the level of the papilla (arrow) with retention of what appears to be an intralesional stone (asterisk).

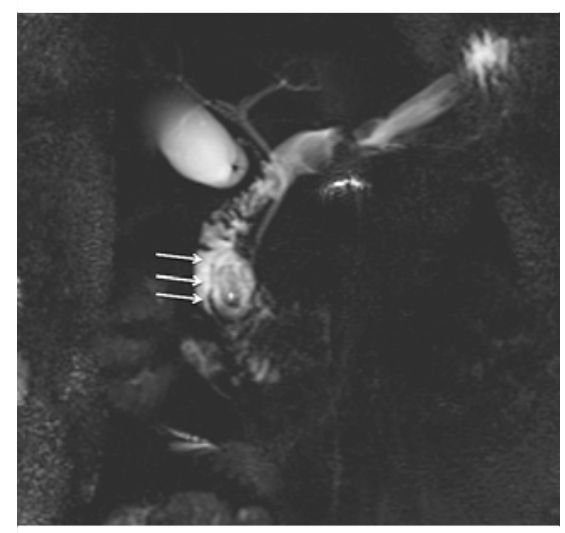

- Fig. 2 Magnetic resonance cholangiogram showing the duodenal duplication cyst (arrows) with the enterolith (asterisk).

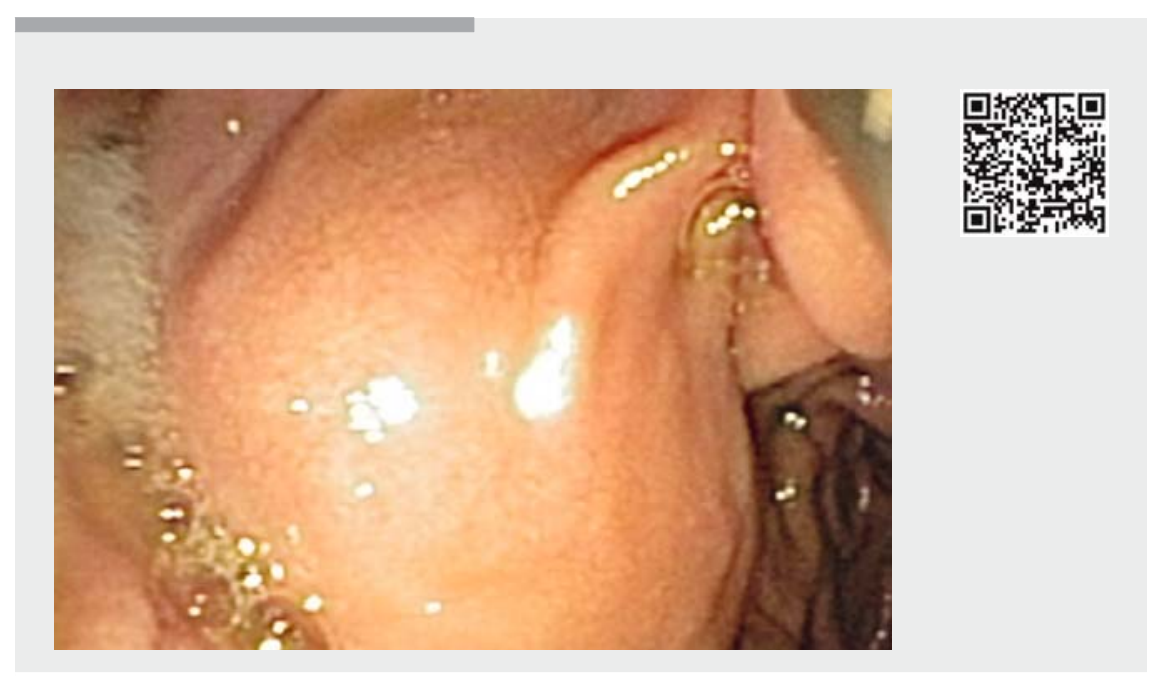

$\square$ Video 1 Endoscopic treatment of a symptomatic duodenal duplication cyst showing inspection of the ampullary region, the papilla being located, resection of the duodenal duplication cyst, and cannulation of the papilla.

Given the fact that the papilla was completely separate from the duodenal duplication cyst and no connection was observed with the common bile duct upon cholangiography, the formation of the enterolith was most probably related to stasis that gave rise to mineral concretion. The anatomic cyst formed a nidus or predisposing factor for such a process to arise. An analogous process has been described for enteroliths in Meckel's diverticulum.

Re-evaluation after 2 months showed clear healing of the locus of resection ( $\triangleright$ Fig.4). Surveillance scheduled after 6 and 12 months continued to show no noticeable problems. 

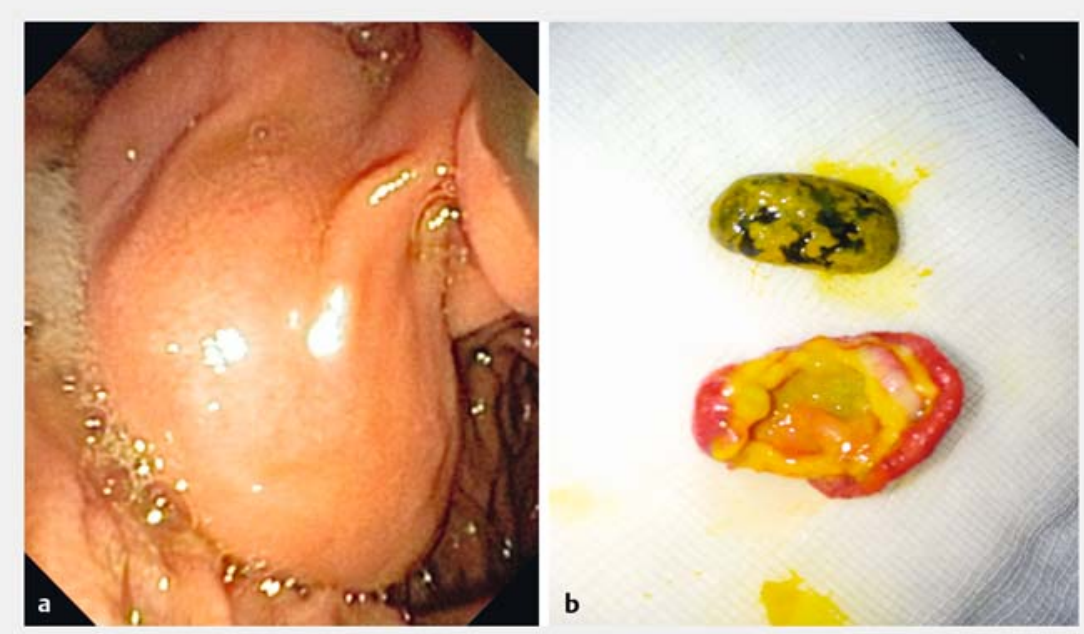

- Fig. 3 Appearance of the duplication cyst: a on endoscopic view; $\mathbf{b}$ after resection, along with the enterolith.

The present case illustrates a rare condition in which a patient presented with a symptomatic duodenal duplication cyst containing a stone, which was managed by endoscopic resection [1 - 3].

Endoscopy_UCTN_Code_TTT_1AO_2AN

\section{Competing interests}

\section{None}

\section{The authors}

Nikkie Schils ${ }^{1}$, Vincent Vandecaveye ${ }^{2}$, Lode Van Overbeke ${ }^{3}$, Wim Laleman ${ }^{1}$

1 Department of Gastroenterology and Hepatology, Section Liver and Biliopancreatic disorders, University Hospitals Leuven, Leuven, Belgium

2 Department of Radiology, University Hospitals Leuven, Leuven, Belgium

3 Department of Gastroenterology, AZ Sint Maarten, Mechelen, Belgium

\section{Corresponding author}

\section{Wim Laleman, MD, PhD}

Department of Liver and Biliopancreatic disorders, University Hospitals Leuven, KU Leuven, Leuven, Belgium

Fax: +32-16-344387

wim.laleman@uzleuven.be

\section{Acknowledgments}

We thank Mr. Ruben Jans for his helpful assistance in the editing of the video.

\section{References}

[1] Bar-Ziv J, Katz R, Nobel M et al. Duodenal duplication cyst with enteroliths: computed tomography and ultrasound diagnosis. Gastrointest Radiol 1989; 14: $220-222$

[2] Leffall LS Jr, Jackson M, Press H et al. Duplication cyst of the duodenum. Arch Surg 1967; 94: 30-34

[3] Antaki F, Tringali A, Deprez P et al. A case series of symptomatic intraluminal duodenal duplication cysts: presentation, endoscopic therapy, and long-term outcome (with video). Gastrointest Endosc 2008; 67: $163-168$

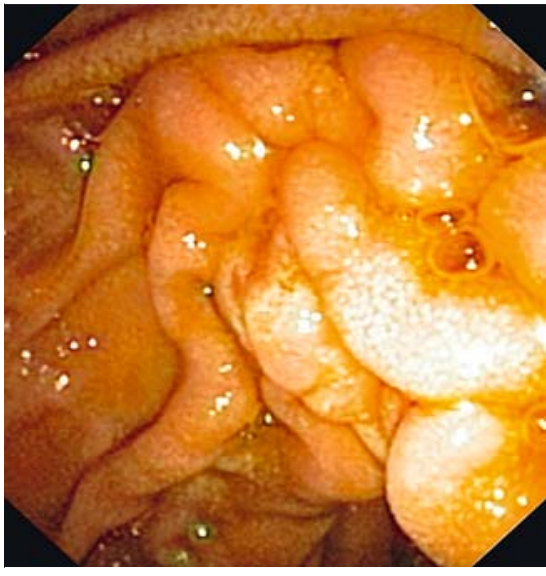

- Fig. 4 Endoscopic re-evaluation 2 months after resection showing complete healing of the area of the resection.

\section{Bibliography}

DOI https://doi.org/10.1055/a-0605-2519

Published online: 9.5.2018

Endoscopy 2018; 50: E184-E185

(c) Georg Thieme Verlag KG

Stuttgart · New York

ISSN 0013-726X

\section{ENDOSCOPY E-VIDEOS}

https://eref.thieme.de/e-videos

回解 Endoscopy E-Videos is a free access online section, reporting 回: on interesting cases and new techniques in gastroenterological endoscopy. All papers include a high quality video and all contributions are freely accessible online.

This section has its own submission website at https://mc.manuscriptcentral.com/e-videos 